\title{
FAKTOR-FAKTOR YANG MEMPENGARUHI KEIKUTSERTAAN \\ BIDAN PRAKTIK MANDIRI PADA PROGRAM JAMINAN KESEHATAN NASIONAL DI KOTA PALANGKA RAYA
}

\author{
Riyanti ${ }^{1}$ Seri Wahyuni ${ }^{2}$ \\ Program Studi Diploma III Kebidanan Poltekkes Kemenkes Palangka Raya \\ Provinsi Kalimantan Tengah \\ Email : riyantihelena@gmail.com
}

\begin{abstract}
ABSTRAK
Upaya penurunan angka kematian ibu dan bayi dilakukan melalui berbagai program termasuk program Jaminan Kesehatan Nasional (JKN). Bidan sangat berperan dalam penurunan $\mathrm{AKI}$ dan $\mathrm{AKB}$, karena bidan merupakan tenaga kesehatan di garis terdepan dan berhubungan langsung dengan masyarakat, dalam memberikan pelayanan yang berkesinambungan dan paripurna. Penelitian ini bertujuan untuk mengetahui faktor- faktor yang memengaruhi keikutsertaan Bidan Praktik Mandiri Pada Program Jaminan Kesehatan Nasional di Kota Palangka Raya.

Pendekatan yang digunakan dalam penelitian ini observasional analitik dan rancangan Cross Sectional. Populasi pada penelitian ini adalah seluruh BPM yang terdapat di Kota Palangka Raya pada tahun 2016. Sampel penelitian berjumlah 105 orang BPM. Analisis univariat dilakukan dengan distribusi frekuensi, untuk analisis bivariat umur, pendidikan, lama praktik, pengetahuan, komunikasi, motivasi, prosedur kerjasama, proses klaim, proses administrasi dan tarif pelayanan menggunakan chi kuadrat $\left(\mathrm{x}^{2}\right)$ dan hubungan antar beberapa variabel dianalisis dengan regresi logistik ganda. Hasil penelitian didapatkan bahwa faktor pendidikan $(p=0,002)$, lama praktik $(p=0,003)$, Prosedur kerjasama $(p=0,000)$, proses klaim $(p=0,042)$, dan proses administrasi $(p=0,001)$ menunjukkan pengaruh signifikan terhadap keikutsertaan BPM pada program JKN. Analisis regresi logistik ganda menunjukkan bahwa faktor pendidikan $(\mathrm{OR}=72,23$; 95\% Cl=2,38 - 218,76), $\mathrm{p}<0,05$, Lama praktik (OR=79,94; 95\% Cl=5,22 - 122,45, $\mathrm{p}<0,05)$, komunikasi (OR=97,98; 95\% Cl=3,10 - 309,40, $\quad \mathrm{p}<0,05)$ dan prosedur administrasi $(\mathrm{OR}=56,25 ; 95 \% \mathrm{Cl}=4,21-750,77, \quad \mathrm{p}<0,05)$ secara simultan memiliki pengaruh signifikan dengan keikutsertaan BPM pada program JKN. Simpulan hasil penelitian terdapat pengaruh pendidikan, lama praktik, komunikasi, prosedur kerjasama, proses klaim, dan proses administrasi dengan keikutsertaan BPM pada program JKN
\end{abstract}

Kata Kunci: Bidan Praktik Mandiri, Jaminan Kesehatan Nasional, Pengetahuan, Motivasi, komunikasi, prosedur kerjasama, klaim, administrasi, tarif pelayanan 
Faktor-Faktor Yang Mempengaruhi Keikutsertaan Bidan Praktik Mandiri Pada Program Jaminan Kesehatan Nasional Di Kota Palangka Raya

\section{ABSTRACT}

Efforts to reduce maternal and infant mortality through various programs including the National Health Insurance program. Midwives play an important role in reducing MMR and IMR, because the midwife is a health worker at the forefront and deal directly with the public, to provide continuous service and complete. This study aims to determine the factors that affect the participation of Independent Midwife Practice On the National Health Insurance Program in the city of Palangkaraya.

The approach used in this study was an observational analytic and cross sectional design. The population in this study are all midwive private practice located in the city of Palangkaraya in 2016. The samples included 105 midwive private practice. Univariate analysis performed by the frequency distribution for bivariate analysis, age, education, length of practice, knowledge, communication, motivation, cooperation procedure, process claims, the administration process and tariff services using chi square $(x 2)$ and the relationships among several variables were analyzed with multiple logistic regression, The result showed that the factors of education $(p=$ $0.002)$, duration of practice $(p=0.003)$, procedure of cooperation $(p=0.000)$, the process claim $(p=0.042)$, and administrative processes $(p=0.001)$ showed a significant effect on the participation of midwive practice of independent Reviewed JKN program. Multiple logistic regression analysis showed that factors of education (OR $=72.23 ; 95 \% \mathrm{Cl}=2.38$ to 218.76), $p$ $<0.05$, Lama practices (OR $=79.94 ; 95 \% \mathrm{Cl}=5.22$ - 122.45, $p<0.05)$, communications $(O R=$ 97.98; $95 \% \mathrm{Cl}=3.10$ to 309.40, $p<0.05)$ and administrative procedures $(\mathrm{OR}=56.25 ; 95 \% \mathrm{Cl}=$ 4.21 to $750.77, p<0.05)$ simultaneously have a significant influence on the program with the participation of midwive private practices JKN. Conclusion The research results are the effect of education, length of practice, communication, cooperation procedure, process claims, and administrative processes with midwive private practices participation in the program JKN

Keywords: midwive private practices, National Health Insurance, knowledge, motivation, communication, cooperation procedure, claims, administrative, service tariff.

\section{PENDAHULUAN}

Kesehatan adalah hak asasi manusia dan investasi untuk keberhasilan pembangunan bangsa. Demikian halnya derajat kesehatan suatu negara salah satunya ditentukan oleh angka kematian ibu (AKI) dan angka kematian bayi (AKB). Pemerintah berupaya keras menurunkan AKI dan AKB melalui berbagai program dimulai dari program Gerakan Sayang Ibu (GSI), Safe motherhood, Making Pregnancy Safer (MPS), desa siaga, P4K, Jampersal hingga program Jaminan Kesehatan Nasional (JKN). Bidan sangat berperan dalam penurunan $\mathrm{AKI}$ dan $\mathrm{AKB}$, kematian ibu dan bayi baru lahir adalah karena bidan sebagai tenaga kesehatan yang berada di garis terdepan dan berhubungan langsung dengan masyarakat, dalam memberikan pelayanan yang berkesinambungan dan paripurna berfokus pada aspek pencegahan melalui pendidikan kesehatan dan konseling, promosi kesehatan, pertolongan persalinan normal dengan berlandaskan kemitraan dan pemberdayaan perempuan serta melakukan deteksi dini pada kasus-kasus rujukan kebidanan (Kemenkes RI,2013).

Faktor terpenting yang dapat menurunkan 
meningkatkan akses ibu hamil terhadap persalinan yang sehat dengan cara memberikan kemudahan pembiayaan untuk menghilangkan hambatan finansial pada ibu hamil dan keluarga, maka pada tahun 2010 Kementerian Kesehatan Republik Indonesia mengeluarkan kebijakan tentang Jampersal. Tujuan dari Jampersal yaitu untuk meningkatkan akses ibu hamil terhadap pelayanan pemeriksaan kehamilan, pertolongan persalinan, perawatan bayi baru lahir, perawatan nifas dan pelayanan keluarga berencana (Kemenkes RI, 2011).

Hasil studi evaluasi Jampersal tahun 2012, menghasilkan evidence yang meyakinkan bahwa Jampersal berhasil mengajak ibu hamil untuk melahirkan di fasilitas kesehatan. Peran aktif dari bidan sebagai ujung tombak pemberi pelayanan kebidanan dan neonatal, ketersediaan obat dan peralatan serta fasilitas yang telah disediakan oleh pemerintah semakin meningkatkan jumlah kunjungan ibu hamil ke fasilitas kesehatan. Masyarakat berpendapat dan mempunyai harapan terhadap program Jampersal agar dapat dilanjutkan hingga saat program JKN diberlakukan. Fakta tersebut menjadi alasan yang kuat program Jampersal dipertahankan keberlangsungannya dalam program JKN dengan berbagai perbaikan dalam proses pelaksanaannya (Rahmawaty, 2013).
World Health Organization (WHO) telah membuat kesepakatan untuk mencapai Universal Health coverage (UHC) di tahun 2014, mengenai kepastian sistem kesehatan untuk setiap warga di suatu negara agar memiliki akses yang adil terhadap pelayanan kesehatan berupa upaya promotif, preventif, kuratif dan rehabilitatif bermutu dengan biaya terjangkau. Undang-undang Nomor 40 tahun 2004 tentang Sistem Jaminan Kesehatan Nasional (SJSN) telah menjawab prinsip dasar dari program UHC yaitu dengan mewajibkan setiap penduduk memiliki akses terhadap pelayanan kesehatan yang menyeluruh atau komprehensif (Aulia, 2011).

Sistem Jaminan Kesehatan Nasional (SJSN) yang lebih dikenal dengan Jaminan Kesehatan Nasional diterapkan dengan pendekatan Universal Health Coverage, yaitu menjamin akses masyarakat terhadap pelayanan kesehatan, baik preventif, promotif, kuratif dan rehabilitatif tanpa harus mengalami kesulitan finansial saat memanfaatkannya. Namun dalam pelaksanaannya masih menjadi hambatan bagi perempuan peserta JKN yang memiliki akses cukup jauh ke puskesmas. Bidan praktik mandiri sebagai penyedia layanan kebidanan yang lebih mudah diakses, karena jumlahnya lebih banyak dan lebih merata penyebarannya, justru tidak dapat diakses pemanfaatannya melalui sistem JKN. Dalam Permenkes Nomor 71 Tahun 2013, bidan praktik mandiri tidak tercantum 

Jaminan Kesehatan Nasional Di Kota Palangka Raya

dalam pelayanan kesehatan yang dapat Apabila BPM tidak dilibatkan dalam JKN, berkerjasama dengan BPJS. Posisi bidan maka dapat menghambat upaya pemerintah praktik mandiri hanya sebagai pengganti menekan AKI dan upaya menggalakkan tenaga kesehatan apabila tidak terdapat Program Keluarga Berencana.

dokter di suatu wilayah tertentu.

Desain asuransi kesehatan yang berbasis masyarakat seperti JKN, membuat kontribusi masyarakat untuk berpartisipasi menjadi lebih tinggi. Menurut Dror, dkk (2006) negara India melakukan penekanan biaya persalinan dengan cara memberikan voucher yang bisa digunakan untuk membayar transportasi saat akan bersalin. Hasil penelitian di Banglades menjelaskan bahwa meskipun biaya persalinan gratis namun dari total pengeluaran langsung hampir $50 \%$ untuk biaya rujukan (Dong dkk, 2004).

Implementasi JKN masih menimbulkan pertanyaan bagi para bidan, karena Bidan Praktek Mandiri (BPM) tidak dapat bekerjasama langsung dengan BPJS Kesehatan dan harus bergabung menjadi jejaring dulu pada fasilitas kesehatan tingkat I (Puskesmas) atau dokter praktek perseorangan. Sosialisasi tentang JKN pada BPM tentang bagaimana mekanisme kerjasama, prosedur, sistem pembayaran klaim dan cakupan pelayanan kebidanan dan neonatal yang ditanggung JKN masih kurang, sehingga Ikatan Bidan Indonesia (IBI) mengharapkan agar BPM dapat bekerjasama langsung dengan BPJS seperti saat program Jampersal dan Jamkesda diberlakukan.

\section{METODOLOGI}

Jenis penelitian ini adalah penelitian deskriptif analitik (non eksperimen), dengan rancangan cross sectional. Populasi penelitian seluruh bidan yang memiliki SIPB di Kota Palangka Raya pada periode bulan Januari sampai Desember Tahun 2015 yang berjumlah 105 orang Bidan Praktik Mandiri. Cara pengambilan sampel pada penelitian ini adalah dengan menggunakan probability sampling dengan teknik Simple Random sampling.

\section{HASIL DAN PEMBAHASAN}

Penelitian ini dilakukan pada bidan Praktik Mandiri yang ada di Wilayah Kota Palangka Raya yang memenuhi kriteria inklusi dan ekslusi.

\section{Tabel 1 Karakteristik Responden}

\begin{tabular}{lcc}
\multicolumn{1}{c}{ Karakteristik } & Frekuensi & Persentase \\
\hline Kerjasama JKN & & \\
Tidak & 81 & $77,1 \%$ \\
Ya & 24 & $22,9 \%$ \\
\hline Umur & & \\
20 - 30 tahun & 22 & $21 \%$ \\
$\geq 30$ tahun & 83 & $79 \%$ \\
\hline Pendidikan & & \\
D I & 15 & $14,3 \%$ \\
D III & 72 & $68,6 \%$ \\
D IV & 10 & $9,5 \%$ \\
S 2 & 8 & $7,6 \%$ \\
\hline
\end{tabular}


Riyanti dan Seri Wahyuni

\begin{tabular}{|c|c|c|c|c|c|}
\hline Lama Praktik & & & Mudah & 30 & $28,6 \%$ \\
\hline$<5$ tahun & 45 & $42,9 \% \%$ & \multirow{3}{*}{$\begin{array}{l}\text { Proses Klaim } \\
\text { Tidak Mudah } \\
\text { Mudah }\end{array}$} & \multirow{3}{*}{$\begin{array}{l}85 \\
20\end{array}$} & \multirow{3}{*}{$\begin{array}{l}81 \% \\
19 \%\end{array}$} \\
\hline$\geq 5$ tahun & 60 & $57,1 \%$ & & & \\
\hline Pengetahuan & & & & & \\
\hline Rendah & 7 & $6.66 \%$ & \multirow{4}{*}{$\begin{array}{l}\text { Proses } \\
\text { Administrasi } \\
\text { Tidak Mudah } \\
\text { Mudah }\end{array}$} & \multirow{4}{*}{$\begin{array}{l}77 \\
28\end{array}$} & \multirow{4}{*}{$\begin{array}{l}73,3 \% \\
26.7 \%\end{array}$} \\
\hline Sedang & 49 & $46,7 \%$ & & & \\
\hline Tinggi & 49 & $46,7 \%$ & & & \\
\hline Motivasi & & & & & \\
\hline Rendah & 44 & $41,9 \%$ & \multirow{3}{*}{$\begin{array}{l}\text { Tarif Pelayanan } \\
\text { Tidak Sesuai } \\
\text { Sesuai }\end{array}$} & & \multirow{3}{*}{$\begin{array}{l}86,7 \% \\
13,3 \%\end{array}$} \\
\hline Tingai & 61 & $58,1 \%$ & & & \\
\hline Motivasi & & & & & \\
\hline Rendah & 44 & $41,9 \%$ & \multirow{3}{*}{\multicolumn{3}{|c|}{ Analisis data secara bivariat dilakukan }} \\
\hline Tinggi & 61 & $58,1 \%$ & & & \\
\hline Komunikasi & & & & & \\
\hline $\begin{array}{l}\text { Tidak } \\
\text { Ya }\end{array}$ & $\begin{array}{l}21 \\
84\end{array}$ & $\begin{array}{l}20 \% \\
80 \%\end{array}$ & \multirow{6}{*}{\multicolumn{3}{|c|}{$\begin{array}{l}\text { dengan mengunakan uji Chi-Square } \\
\text { dimaksudkan untuk menguji hubungan antara } \\
\text { faktor-faktor yang mempengaruhi } \\
\text { keikutsertaan bidan praktik mandiri dalam } \\
\text { bekerjasama dengan JKN. Berikut hasil } \\
\text { pengujian hubungan tersebut secara bivariat: }\end{array}$}} \\
\hline Pengetahuan & & & & & \\
\hline Rendah & 7 & $6.66 \%$ & & & \\
\hline Sedang & 49 & $46,7 \%$ & & & \\
\hline Tinggi & 49 & $46,7 \%$ & & & \\
\hline $\begin{array}{l}\text { Prosedur } \\
\text { Kerjasama } \\
\text { Tidak Mudah }\end{array}$ & 75 & $71,4 \%$ & & & \\
\hline
\end{tabular}

Tabel 3. Pengujian Hubungan Faktor-Faktor yang Mempengaruhi Keikutsertaan Bidan Praktik Mandiri dalam Bekerjasama dengan JKN

\begin{tabular}{|c|c|c|c|c|c|}
\hline \multirow{2}{*}{ Variabel } & \multicolumn{2}{|c|}{ Keikutsertaan JKN } & \multirow{2}{*}{$\begin{array}{c}\text { Chi- } \\
\text { Square }\end{array}$} & \multirow{2}{*}{ p-value } & \multirow{2}{*}{ Keterangan } \\
\hline & Tidak & Ya & & & \\
\hline \multicolumn{6}{|l|}{ Umur } \\
\hline$-20-30$ th & $19(18.1 \%)$ & $3(2.9 \%)$ & 1.342 & 0.247 & Tidak Signifikan \\
\hline$->30$ th & $62(59 \%)$ & $21(20 \%)$ & & & \\
\hline \multicolumn{6}{|l|}{ Pendidikan } \\
\hline - DI & $14(13.3 \%)$ & $1(1 \%)$ & 14.338 & 0.002 & Signifikan \\
\hline - DIII & $59(56.2 \%)$ & $13(12.4 \%)$ & & & \\
\hline - DIV & $4(3.8 \%)$ & $6(5.7 \%)$ & & & \\
\hline - S2 & $4(3.8 \%)$ & $4(3.8 \%)$ & & & \\
\hline \multicolumn{6}{|l|}{ Lama Praktek } \\
\hline$-<5$ th & $41(39 \%)$ & $4(3.8 \%)$ & 8.714 & 0.003 & Signifikan \\
\hline$-\geq 5$ th & $40(38.1 \%)$ & $20(19 \%)$ & & & \\
\hline \multicolumn{6}{|l|}{ Pengetahuan } \\
\hline - Rendah & $6(5.7 \%)$ & $1(1 \%)$ & 0.370 & 0.831 & Tidak Signifikan \\
\hline - Sedang & 37 (35.2\%) & $12(11.4 \%)$ & & & \\
\hline - Tinggi & $38(36.2 \%)$ & $11(10.5 \%)$ & & & \\
\hline \multicolumn{6}{|l|}{ Motivasi } \\
\hline - Rendah & $30(28.6 \%)$ & $14(13.3 \%)$ & 3.449 & 0.063 & Tidak Signifikan \\
\hline - Tinggi & $51(48.6 \%)$ & $10(9.5 \%)$ & & & \\
\hline
\end{tabular}


Faktor-Faktor Yang Mempengaruhi Keikutsertaan Bidan Praktik Mandiri Pada Program Jaminan Kesehatan Nasional Di Kota Palangka Raya

\begin{tabular}{|c|c|c|c|c|c|}
\hline \multicolumn{6}{|l|}{ Komunikasi } \\
\hline - Tidak & $19(18.1 \%)$ & $2(1.9 \%)$ & 2.647 & 0.104 & Tidak Signifikan \\
\hline$-\mathrm{Ya}$ & $62(59 \%)$ & $22(21 \%)$ & & & \\
\hline \multicolumn{6}{|c|}{ Prosedur Kerjasama } \\
\hline - Tidak Mudah & 65 (61.9\%) & 10 (9.5\%) & 13.503 & 0.000 & Signifikan \\
\hline - Mudah & $16(15.2 \%)$ & $14(13.3 \%)$ & & & \\
\hline \multicolumn{6}{|l|}{ Proses Klaim } \\
\hline - Tidak Mudah & $69(65.7 \%)$ & $16(15.2 \%)$ & 4.118 & 0.042 & Signifikan \\
\hline - Mudah & $12(11.4 \%)$ & $8(7.6 \%)$ & & & \\
\hline \multicolumn{6}{|c|}{ Proses Administrasi } \\
\hline - Tidak Mudah & 66 (62.9\%) & $11(10.5 \%)$ & 12.031 & 0.001 & Signifikan \\
\hline - Mudah & $15(14.3 \%)$ & $13(12.4 \%)$ & & & \\
\hline \multicolumn{6}{|l|}{ Tarif Pelayanan } \\
\hline - Tidak Sesuai & 72 (68.6\%) & $19(18.1 \%)$ & 1.514 & 0.218 & Tidak Signifikan \\
\hline - Sesuai & $9(8.6 \%)$ & $5(4.8 \%)$ & & & \\
\hline
\end{tabular}

Pengujian secara bivariat dengan uji Chi-

Pengujian secara multivariat dengan square dapat diketahui bahwa dari sepuluh menggunakan analisis regresi logistik faktor yang diteliti, terdapat 5 (lima) faktor dilakukan untuk mengetahui Faktor-Faktor yaitu pendidikan, lama praktek, prosedur, yang Mempengaruhi Keikutsertaan Bidan klaim, dan administrasi memiliki hubungan Praktik Mandiri pada Program Jaminan yang signifikan dengan keikutsertaan Bidan Kesehatan Nasional. Berikut hasil pengujian Praktik Mandiri untuk bekerjasama dengan dengan menggunakan analisis regresi logistik JKN.

Tabel 4. Pengujian Pengaruh Variabel Secara Parsial

\begin{tabular}{lccccccc} 
& & & & & \multicolumn{2}{c}{ Cl 95\% } & \\
\cline { 1 - 1 } \multicolumn{1}{c}{ Variabel Bebas } & B & Wald & p-value & Odd ratio & Lower & Upper & Keterangan \\
\hline Umur & -1.466 & 1.274 & 0.259 & 0.23 & 0,18 & 2,95 & Tidak Signifikan \\
\hline Pendidikan & & 7.801 & 0.050 & & & & Signifikan \\
\hline - (DIII) & 2.659 & 2.946 & 0.086 & 14.27 & 0,69 & 297,16 & Tidak Signifikan \\
\hline - (DIV) & 4.280 & 6.049 & 0.014 & 72.23 & 2,38 & 2187,62 & Signifikan \\
\hline - (S2) & 5.630 & 4.927 & 0.026 & 278.68 & 1,93 & 4018,85 & Signifikan \\
\hline Lama Praktek & 4.381 & 9.901 & 0.002 & 79.93 & 5,22 & 1224,59 & Signifikan \\
\hline Pengetahuan & & 0.057 & 0.972 & & & & Tidak Signifikan \\
\hline - Pengetahuan (Sedang) & 0.202 & 0.018 & 0.894 & 1.22 & 0,06 & 23,69 & Tidak Signifikan \\
\hline - Pengetahuan (Tinggi) & 0.324 & 0.047 & 0.828 & 1.38 & 0,07 & 25,41 & Tidak Signifikan \\
\hline Motivasi & -0.819 & 1.004 & 0.316 & 0.44 & 0,09 & 2,19 & Tidak Signifikan \\
\hline
\end{tabular}


Riyanti dan Seri Wahyuni

\begin{tabular}{lccccccc}
\hline Komunikasi & 4.585 & 6.775 & 0.009 & 97.98 & 3,10 & 3094 & Signifikan \\
\hline Prosedur kerjasama & 0.880 & 1.029 & 0.310 & 2.41 & 0,44 & 13,21 & Tidak Signifikan \\
\hline Proses Klaim & -0.534 & 0.188 & 0.665 & 0.58 & 0,05 & 6,58 & Tidak Signifikan \\
\hline Proses Administrasi & 4.030 & 9.290 & 0.002 & 56.25 & 4,21 & 750,78 & Signifikan \\
\hline Tarif Pelayanan & 0.785 & 0.397 & 0.529 & 2.19 & 0,19 & 25,17 & Tidak Signifikan \\
\hline Constant & -11.488 & 8.749 & 0.003 & 0.000 & & & Signifikan \\
\hline
\end{tabular}

Berdasarkan hasil analisis regresi logistik didapatkan variabel pendidikan, lama praktek, komunikasi, dan administrasi secara parsial memberikan pengaruh yang signifikan terhadap keikutsertaan Bidan Praktik Mandiri pada Program JKN.

Variabel pendidikan P-value lebih dari 0.05 menunjukkan bahwa tidak terdapat perbedaan keikutsertaan Bidan Praktik Mandiri pada Program JKN antara bidan yang berpendidikan DI dengan DIII. BPM yang berpendidikan DIV berpeluang mengikuti kerjasama JKN sebesar 72,23 kali lebih tinggi daripada BPM yang berpendidikan Diploma I.

Tingkat pendidikan bidan memiliki pengaruh yang bermakna dalam keikutsertaan BPM pada program JKN. Hasil penelitian ini terbukti bahwa BPM yang berpendidikan lebih tinggi, lebih cenderung mengikuti kerjasama dengan program JKN.Penelitian yang dilakukan di Jakarta Pusat (2013) menunjukkan bahwa adanya korelasi positif antara tingkat pendidikan sumber daya manusia dengan status kesehatan (Pradono J dan Ning S, 2013). Melalui pendidikan dapat meningkatkan keterampilan profesional dan pengetahuan spesifik yang masih relevan dengan pengetahuan umum. Akhirnya pendidikan dapat membentuk disposisi, perilaku dan kepribadian. Di sekolah orang disosialisasikan untuk menjadi lebih mandiri, lebih memotivasi diri, percaya diri, dan dapat menciptakan modal sosial. Adapun argumen status pencapaian, lamanya bersekolah dapat menyebabkan individu terpapar dengan lingkungan yang semakin kompleks dan mengarah peningkatan kognitif, Modal manusia yang diperoleh dari sekolah dapat meningkatkan kontrol dan dapat dirasakan dalam kehidupan.

Machenbach dan Bakker yang menuliskan beberapa strategi komprehensif di negara-negara Eropa untuk mengurangi kesenjangan kesehatan (Mackenbach JP \& M. Bakker, 2003). Mereka berpendapat bahwa di Eropa Inggris, Belanda dan Swedia telah membuat kemajuan yang signifikan dalam pengembangan kesehatan pada seluruh penduduk dengan memperkenalkan paket kebijakan dan intervensi yang bersifat komprehensif. Penekanan dari paket tersebut terutama difokuskan pada penanganan faktor seperti pendidikan, pekerjaan, dan 

Jaminan Kesehatan Nasional Di Kota Palangka Raya

pendapatan (Michael Link, 2006). yang bertambah maju kearah positif, memiliki Peningkatan tingkat pendidikan bidan akan kecakapan (pengetahuan kerja) yang memberikan kesempatan bidan untuk dapat lebih memahami tentang program JKN dan bekerjasama dengan BPJS Kesehatan.

Peluang BPM dengan masa praktik $\geq 5$ tahun 79,94 kali lebih tinggi untuk mengikuti kerjasama program JKN daripada BPM dengan masa praktik $<5$ tahun. Semakin lama masa praktik BPM, peluang untuk mengikuti program kerjasama dengan JKN semakin tinggi. Semakin lama masa praktik BPM, peluang untuk mengikuti program kerjasama dengan JKN semakin tinggi. Hasil penelitian di Bogor (2015) pengalaman kerja seorang bidan yang lebih dari 5 tahun telah mengalami proses perkembangan, menurut ilmu psikologi perkembangan terjadi akibat dari proses kematangan dan pengalaman dari lingkungan, dengan demikian pengalaman dalam penanganan pasien seharusnya sudah baik dan pengambilan keputusan yang diambil dalam keadaan penanganan gawat darurat maupun tidak gawat darurat seharusnya sudah profesional (Nawati dan Eriati, 2016). Lama kerja merupakan pengalaman individu yang akan menentukan pertumbuhan dalam pekerjaan dan jabatan. Seperti diungkapkan oleh Andi Mappiare bahwa pertumbuhan jabatan dalam pekerjaan dapat dialami oleh seseorang hanya apabila dijalani proses belajar dan berpengalaman dan diharapkan orang yang bersangkutan memiliki sikap kerja

bertambah baik serta memiliki keterampilan kerja yang bertambah dalam kualitas dan kuantitas (Departemen Kesehatan Republik Indonesia, 2007)

Variabel komunikasi berpengaruh signifikan terhadap keikutsertaan Bidan Praktik Mandiri pada Program JKN. Peluang BPM yang telah mendapatkankan informasi tentang JKN 97,984 kali lebih tinggi untuk mengikuti kerjasama program JKN daripada BPM yang tidak mendapatkan informasi tentang JKN.

BPM yang mendapatkan informasi tentang JKN berpeluang untuk mengikuti program kerjasama dengan JKN.Sosialisasi tentang JKN pada BPM tentang bagaimana mekanisme kerjasama, prosedur, sistem pembayaran klaim dan cakupan pelayanan kebidanan dan neonatal yang ditanggung JKN masih kurang, sehingga IBI mengharapkan agar BPM dapat bekerjasama langsung dengan BPJS Kesehatan seperti saat program Jampersal dan Jamkesda diberlakukan. Apabila BPM tidak dilibatkan dalam JKN, maka dapat menghambat upaya pemerintah menekan AKI dan upaya menggalakkan program KB (IBI, 2014).

Sejak diberlakukan Januari 2014 yang lalu, implementasi kebijakan JKN pada pelayanan kebidanan dan neonatal sarat dengan berbagai permasalahan, diantaranya 
masih belum meratanya sosialisasi tentang JKN pada bidan-bidan (Zakiah, 2015). Kurangnya informasi tentang kerjasama BPM dengan program JKN secara tidak langsung akan menghambat keinginan untuk berpartisipasi dengan program JKN Sosialisasi menjadi faktor yang penting untuk keberhasilan pelaksanaan Program Jampersal. Hal tersebut menujukkan bahwa masih ada sasaran yang tidak memanfaatkan Jampersal 66,70\% karena tidak tahu adanya Jampersal. Disini juga terlihat bahwa peran Bidan juga sangat memengaruhi melaksanakan pelayanan atau tidak terhadap Jampersal (Kemenkes, 2011). Menteri Kesehatan menyatakan bahwa masyarakat selalu mengharapkan pelayanan publik termasuk pelayanan kesehatan yang sebaikbaiknya dan diselenggarakan secara profesional yang meliputi upaya promotif, preventif, kuratif, dan rehabilitatif. Untuk menyelenggarakan pelayanan kesehatan yang sebaik-baiknya diperlukan komitmen dari seluruh pihak terkait baik pemerintah, swasta, dan masyarakat termasuk organisasi profesi, di antaranya adalah IBI.

Menurut Donabedian (1980) dalam Supriyanto, (2007) ada tiga elemen layanan jasa kesehatan yaitu 1) technical care, 2) interpersonal care, 3) amenity. Technical care terkait dengan ilmu kedokteran, keperawatan dan kesehatan masyarakat, sedangkan interpersonal care adalah komunikasi pemberi jasa dan penerima jasa untuk membantu upaya beralannya technical care lebih ke arah seni dan technical care adalah sains. Dimensi ketiga yaitu Amenity adalah kenyamanan ruangan, kebersihan ruangan, waktu tunggu pemeriksaan, prosedur admisi dan sebagainya. Kualitas jasa atau pelayanan dimulai dari kebutuhan pelanggan dan berakhir pada persepsi pelanggan (Kotler,1997). Hal ini berarti citra kualitas yang baik bukan berasal dari penyedia jasa, melainkan dari sudut pandang atau persepsi pelanggan. Pelangganlah yang mengkonsumsi dan menikmati jasa, sehingga merekalah yang seharusnya menilai kualitas, manfaat atau performance dari jasa tersebut. Namun komitmen tersebut kurang didukung oleh sebagian BPM yang berada di wilayah kota Palangka Raya, mereka enggan mengikuti program JKN dikarenakan urusan administrasi yang tidak mudah, proses klaim yang berbelit serta nilai nominal yang dirasakan kurang memadai karena masih dibawah standart Bidan Praktik BPM.

Prosedur kerjasama sebagai salah satu faktor yang memengaruhi BPM untuk bekerja sama dengan BPJS Kesehatan di Kota Palangka Raya. Mekanisme kerjasama BPM dengan program JKN diatur dalam sistem jejaring, dimana seorang bidan dapat bekerjasama dengan BPJS Kesehatan selaku penyelenggara JKN melalui dokter keluarga. Dokter keluarga akan bekerjasama dengan 

Jaminan Kesehatan Nasional Di Kota Palangka Raya

BPM dalam hal pelayanan kebidanan dan neonatal, namun pada kenyataannya dokter sering mengambil alih tugas tersebut.

Mekanisme kerjasama antara BPM dengan program JKN yang diselenggarakan oleh BPJS Kesehatan adalah melalui dokter keluarga. Menurut Peraturan Menteri Kesehatan Nomor 59 tahun 2014, menyatakan bahwa dokter harus memiliki jejaring bidan, khusus untuk memberikan pelayanan kebidanan dan neonatal. Dokter keluarga dapat bekerjasama dengan 1 sampai 3 orang bidan, sedangkan bidan hanya boleh bekerjasama dengan satu dokter keluarga saja. Sistem jejaring ini baru mulai diterapkan sejak 1 Januari 2015, karena diharapkan adanya kolaborasi antara dokter keluarga dengan bidan. Implementasi JKN masih menimbulkan pertanyaan bagi para bidan, karena BPM tidak dapat bekerjasama langsung dengan BPJS Kesehatan dan harus bergabung menjadi jejaring dulu pada fasilitas kesehatan tingkat I (Puskesmas) atau dokter praktek perseorangan.

Hasil penelitian Yandrizal,dkk (2013) terkait analisis kebijakan jaminan kesehatan kota Bengkulu dalam upaya efisiensi dan efektifitas pelayanan di puskesmas menyatakan bahwa kebijakan Jamkeskot Bengkulu dilaksanakan belum menerapkan prinsip asuransi, dimana penyelenggara berfungsi mengendalikan mutu dan biaya pelayanan kesehatan yang diberikan baik di pelayanan dasar/primer maupun di pelayanan rujukan.

Variabel proses administrasi berpengaruh signifikan terhadap keikutsertaan Bidan Praktik Mandiri pada Program JKN. Peluang BPM yang menganggap mudah proses administrasi, 56,25 kali lebih tinggi untuk mengikuti kerjasama program JKN daripada BPM yang menganggap tidak mudah. Kemudahan proses administrasi yang berhubungan dengan pelayanan kebidanan yang diberikan, mampu meningkatkan keikutsertaan BPM pada program JKN. Penelitian ini didukung hasil penelitian di Kota Binjai (2012) menunjukkan bahwa distribusi frekuensi menurut persepsi tentang prosedur pembuatan PKS (Perjanjian Kerja Sama) diketahui bahwa responden yang menyatakan mudah 11 orang $(18,3 \%)$, dan sulit 49 orang $(81,7)$. Praktek bidan merupakan salah satu elemen yang menentukan keberhasilan pencapaian tujuan jampersal karena mempermudah akses masyarakat terhadap persalinan oleh tenaga kesehatan, khususnya bagi masyarakat yang bertempat tinggal jauh dari puskesmas atau rumah sakit.

Proses klaim sebagai salah satu faktor yang mempengaruhi BPM untuk bekerja sama dengan BPJS Kesehatan di Kota Palangka Raya. Kebijakan pemotongan administrasi untuk BPM yang bekerjasama dengan JKN diharapkan pemerintah daerah meniadakan pemotongan tersebut. Kurangnya klaim yang 
diterima oleh bidan akan sangat memengaruhi kinerja bidan selanjutnya. Proses klaim juga menjadi salah satu hambatan. Proses klaim memerlukan banyak persyaratan serta buktibukti yang harus dilengkapi yang menyebabkan tugas bidan dalam menangani satu pasien bertambah banyak serta butuh waktu untuk pencairan dana, sedangkan jika tidak melalui program Jampersal bidan langsung menerima dana dari pasien. Hal ini dikarenakan proses yang harus dilakukan pada program-program pemerintah sebelumnya sering menyulitkan para bidan (Mayona H dkk, 2012). BPM dipacu untuk bekerjasama dengan JKN agar dapat memberikan pelayanan yang merata kepada semua lapisan masyarakat dan jangan sampai memotong honor bidan tersebut. Perlu disusun suatu acuan berapa jumlah total klaim yang dapat dipotong sebagai biaya administrasi sehingga tidak semua dipotong. Jumlah klaim yang rendah ditambah potongan dapat memengaruhi kinerja dari bidan.

\section{Kesimpulan}

Berdasarkan hasil penelitian, maka disimpulkan semakin tinggi tingkat pendidikan bidan praktik, Semakin lama masa praktik mandiri, prosedur kerjasama dan proses klaim yang mudah,proses administrasi yang mendukung serta informasi yang cukup akan memberi peluang bagi BPM untuk bekerjasama melaksanakan program BPJS
Kesehatan pada Jaminan Kesehatan

Nasional.

\section{DAFTAR PUSTAKA}

Kemenkes RI. 2013. Buku Pegangan Sosialisasi Jaminan Kesehatan Nasional (JKN) dan Sistem Jaminan Sosial Nasional. Jakarta. Kemenkes RI. Bahan Paparan Jaminan Kesehatan Nasional (JKN) dalam Sistem Jaminan Sosial Nasional. Jakarta.

Kementerian Kesehatan RI, 2011. Peraturan Menteri Kesehatan Republik Indonesia nomor. 2562/MENKES/PER/XII/2011 tentang Petunjuk Teknis Jaminan Persalinan, Jakarta.

Rahmawaty, T. 2012. Riset Evaluatif Implementasi Jaminan Persalinan. Laporan Penelitian, Pusat Humaniora, Kebijakan Kesehatan dan pemberdayaan masyarakat. Surabaya.

Kemenhumkam, 2004. Undang-undang RI Nomor 40 tahun 2004 tentang Sistem Jaminan Sosial Nasional.

Aulia,2011. "Analisis faktor yang berhubungan dengan pemanfaatan pelayanan Ante Natal Care oleh ibu peserta Jampersal di wilayah kerja Puskesmas Pocol". Semarang: Universitas Dian Nuswantoro.

Kementerian Kesehatan RI. 2013. Peraturan Menteri Kesehatan nomor 71 tahun 2013 tentang Pelayanan Kesehatan pada JKN

Dror, D.M.dkk.2006. Health insurance benefit packages prioritized by low-income client in india: the tree criteria to estimate effectiveness of choice. Journal of social science \& Medicine 64. 884-896

Pradono J dan Ning S. 2013. Hubungan Antara Tingkat Pendidikan, Pengetahuan Tentang Kesehatan Lingkungan, Perilaku Hidup Sehat Dengan Status Kesehatan. Tersedia diejournal.litbang.depkes.go.id.

Vol 17. No.1.pp.89-95

Mackenbach JP, M. Bakker. 2003. Tackling Socioeconomic Inequalities in Health: Analysis of European Experiences. European Network on Interventions and 
Policies to Reduce Inequalities in Health. Supriyanto, 2007, Strategi Pemasaran Jasa The Lancet, vol. 362, no. 9393, pp. 14091414.

Michael Link, 2006. The Fermat Point of a Hyperbolic Triangle. BA. Bellarmine university

Nawati dan Eriati.2016. Hubungan antara Partisipasi Bidan Praktik Mandiri (BPM), Perjanjian Kerjasama (PKS) dan Sosialisasi dengan Pelaksanaan Program JampersalDi Kota Bogor.Jurnal Kesehatan. 7 (1). 165-175.

Ikatan Bidan Indonesia. 2014. Surat Edaran Nomor 117/SE/PPIBI/I//2014 tentang pelayanan Kebidanan di Era Jaminan Kesehatan Nasional (JKN)

Zakiah. 2015. Faktor Individual Dan Faktor Struktural Yang Berperan Dalam Keikutsertaan Bidan Praktek Mandiri Pada Program Jaminan Kesehatan Nasional Di Kabupaten Tabanan. Tesis. Universitas Udayana. Denpasar.

Pelayanan Kesehatan, AKK Fakultas Kesehatan Masyarakat Unair, Surabaya

Kotler,P., dan Anderson,1997, Strategi Pemasaran Sosial untuk Organisasi Nirlaba, Gajah Mada University Press, Yogjakarta.

Kemenkes RI.2014. Peraturan Menteri Kesehatan nomor 59 tahun 2014 tentang Standar Tarif JKN.

Mayona H, Nasution SK, Rusmalawaty.2012. Pengaruh Persepsi Bidan Praktek Swasta Tentang Program Jampersal Terhadap Kemauan Bidan Menjadi Provider Program Jampersal di Kota Binjai Tahun 2012. USU. Medan.

Yandrizal, dkk (2013). " Analisis Kebijakan Jaminan Keshatan Kota Bengkulu Dalam Upaya Efisiensi Dan Efektifitas Pelayanan Di Puskesmas" Sumatera: Universitas sumatera utara 